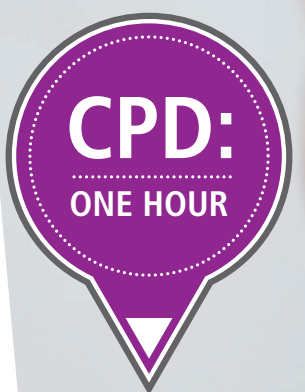

\title{
A guide to oral piercings
}

\section{CPD}

questions

This article has four CPD questions attached to it which will earn you one hour of verifiable CPD. To access the free BDA CPD hub, go to

\section{E. M. King, ${ }^{* 1}$ E. Brewer ${ }^{2}$ and P. Brown}

Introduction The prevalence of oral piercings in the UK is increasing. Consequently, the dental profession is encountering an increasing number of complications associated with piercings. Providing patient preventative advice regarding piercing complications is important, however the level of advice offered by UK dentists is currently unknown. Aims The aim of this survey was to establish the current knowledge, attitudes and behaviours of dentists regarding advice provided to patients with oral piercings. Methods A questionnaire was sent to 200 dentists across Wales with questions regarding perceived confidence in providing advice, type of advice provided, the sources dentists use to acquire knowledge and the perceived need for further professional information. Results Fifty-three dentists responded. Only $24.5 \%$ were very confident discussing piercing complications. The advice provided varied markedly, with the majority (73.6\%) reporting they had acquired knowledge through experience alone. Only one dentist reported providing written information and $83 \%$ responded that they would like to have access to printed information directed at patients. Conclusions The results of this survey suggest that dental professionals are not fully confident discussing risks and preventative advice with patients. To address this, patient information leaflets have been developed to encourage dentists to discuss complications associated with oral piercings with patients.

\section{Introduction}

Body modification, the purposeful alteration of normal human anatomy to achieve a desired appearance, is a popular practice that has led to a rise in the prevalence of oral piercings. In 1992, the first report relating to oral piercing appeared in the dental literature titled 'Tongue piercing: a new fad in body art.' However, rather than a fad, oral piercings have become increasingly popular. Common sites for oral piercings include the tongue (Fig. 1) and lips (Fig. 2) however piercing of alternative anatomical sites such as the cheeks (Figs 3 and 4) and frenulae (Fig. 5), is becoming more prevalent., ${ }^{2,3}$ Oral piercings have been a recent topic of debate in the Welsh Government, and in May 2017 a new Public Health (Wales) Bill was accepted by the National Assembly for Wales to ban all intimate piercing, which includes tongue piercing, before the age of 18 . To establish the current attitudes of the dental profession towards oral piercings, a national survey was conducted among General Dental Practitioners (GDPs) across Wales. Furthermore, a literature review was conducted to establish the current global trends in oral piercings and discuss the potential complications resulting from such body modifications.

\section{Legislation}

Following the death of a Sheffield teenager from septicaemia caused by a lip piercing in 2002 , the risks of body piercing were discussed in the House of Commons. ${ }^{4,5}$ As a result, a voluntary code of practice was implemented for piercers which included guidance regarding the practice of body piercing, specific recommendations for hygienic procedures, checking medical history before piercing and the prevention of piercing individuals below 16 years of age unless parental consent is given. This code of practice is summarised in the document 'Advice and Safe Practice for Body Piercing - Guidance for Operators' produced by the British Body Piercing Association. ${ }^{6}$ It is unknown how many 
piercers have adopted this code of practice and therefore compliance can vary between establishments.

Currently the legislation for licensing and registration of piercing establishments varies between local authorities. In England and Wales, local authorities have the power to apply the Health and Safety at Work Act 1974 to impose infection control and safety requirements. Furthermore, there are specifications stated in the Local Government (Miscellaneous Provisions) Act 1982 and the Local Government Act 2003 for local authorities in England and Wales to require the registration of individuals providing body piercings. ${ }^{8}$ The Local Government Act 2003 also stipulates standards of cross infection control. With the aim of preventing transmission of infectious diseases, the Health and Safety Executive have produced the SR12 publication to help piercers comply with the Control of Substances Hazardous to Health Regulations (COSHH) 2002. ${ }^{9}$ Local authorities can choose whether to adopt and enforce these guidelines in addition to their own byelaws; therefore piercing standards vary across the UK.

While many piercing establishments enforce their own age restrictions, there are currently no laws restricting piercings for minors in England. Many local authorities have developed licensing frameworks that make it possible to state a minimum age; however there are inconsistencies across the UK. Some local councils prohibit cosmetic piercing under 16 years of age whereas some state 18 years of age. ${ }^{10-12}$ In Scotland, individuals under 16 are required to have parental consent before undergoing any piercing. In Northern Ireland, the piercing of nipples and genitalia of children under the age of 16 is regarded as indecent assault under sexual offences legislation, and can lead to prosecution.

The Welsh Government has raised serious concerns about the medical implications associated with intimate piercings, and the potential vulnerability of young people receiving such piercings. In 2015, the Welsh Government introduced a Public Health (Wales) Bill which included a clause to ban all intimate piercing before the age of 18 . The Welsh Dental Committee (WDC) responded to the consultation and strongly suggested that intimate piercing should include tongue piercing, and as a result tongue piercing was added to the list of intimate piercings. The Public Health (Wales) Bill was accepted by the National Assembly for Wales in May 2017 and the age for intimate piercing, including tongue piercing, has been raised to 18 years old. This is now in keeping with similar legislation such as tattooing of minors and
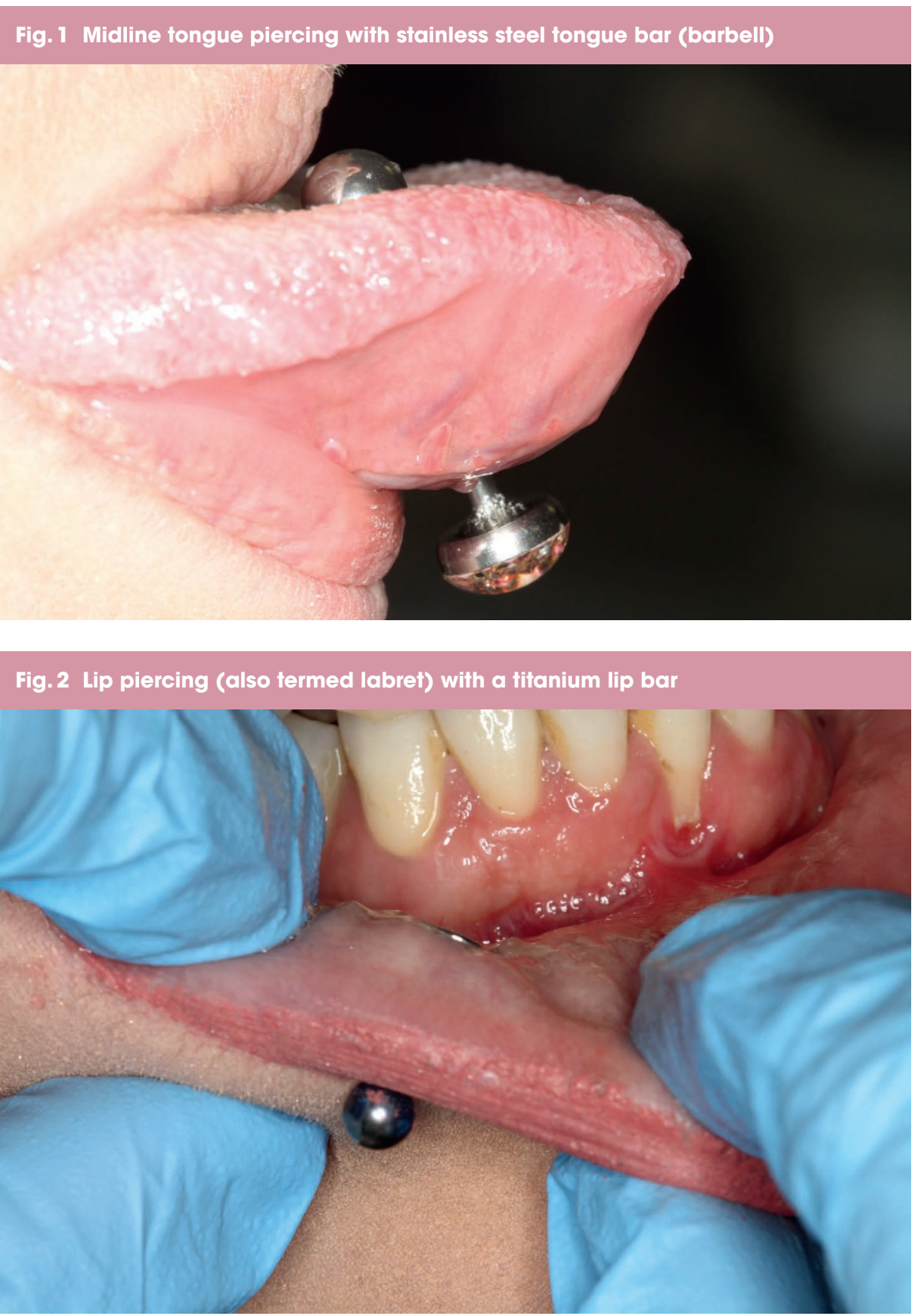

Fig. 3 Cheek piercing viewed intra-orally with titanium bar in situ

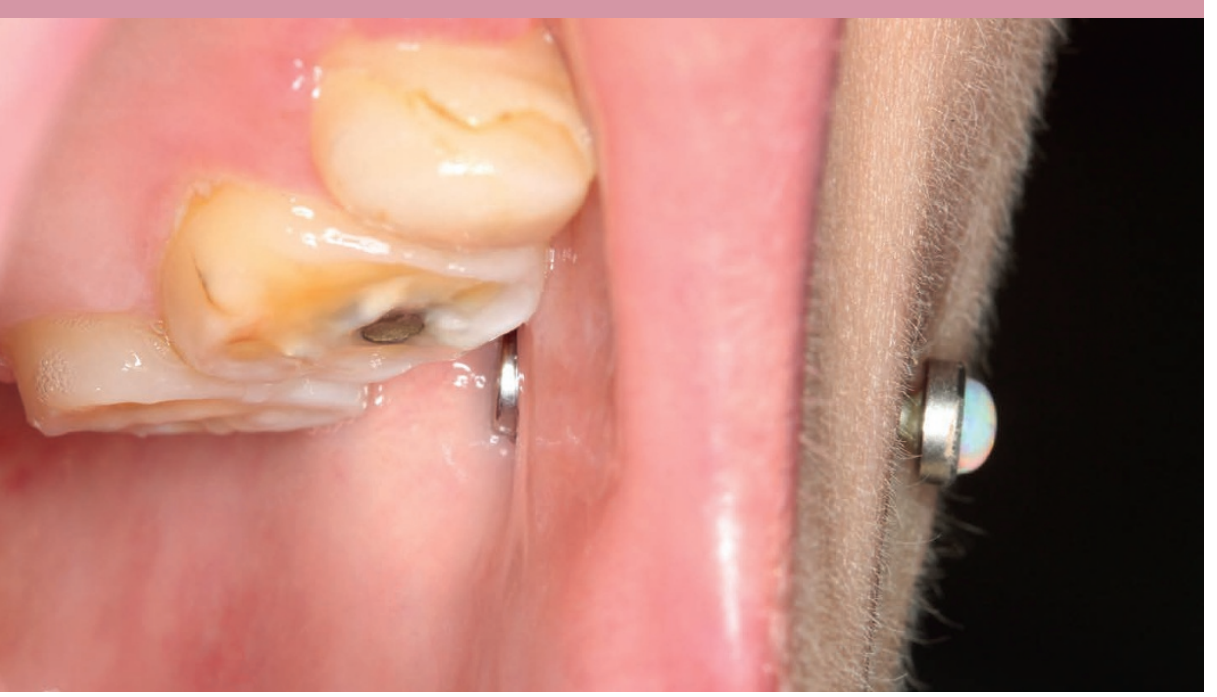




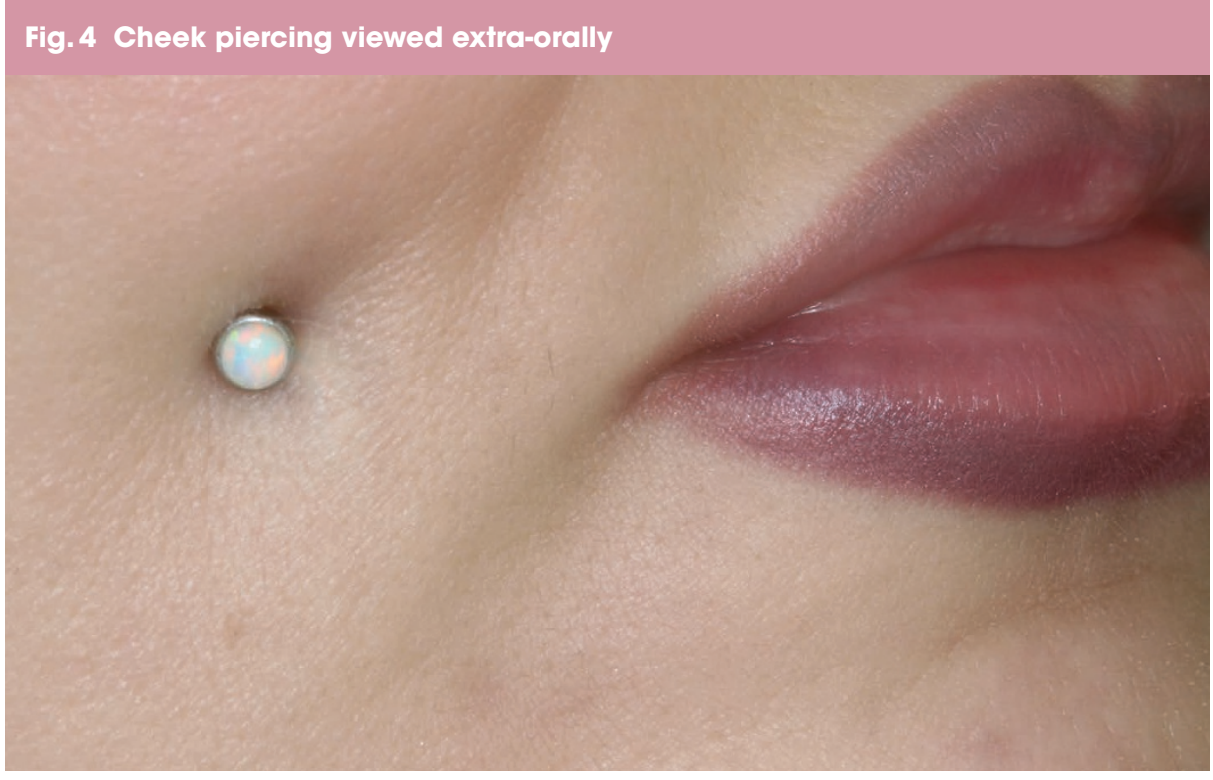

Fig. 5 Piercing of the lingual frenulum with stainless steel bar in place. Note the accumulation of plaque on the ball ends of the piercing

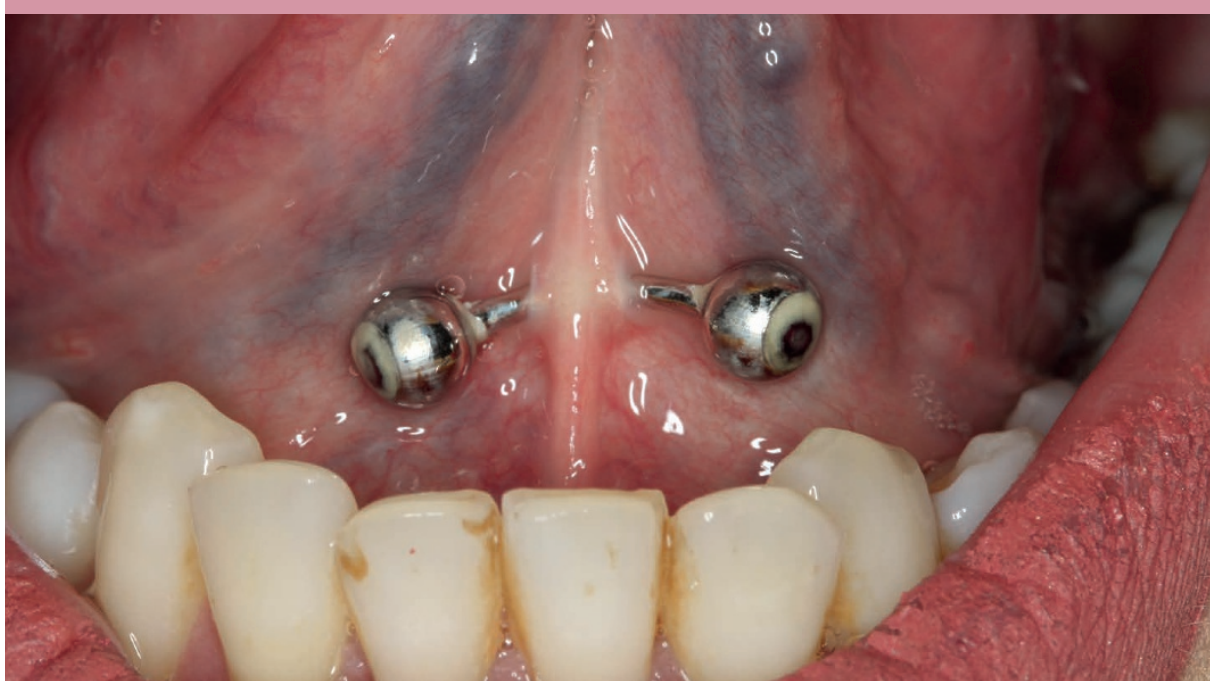

TONGUE PIERCING WAS THE SECOND

\section{MOST COMMON BODY PIERCING}

\section{RESULTING IN COMPLICATIONS}

\section{(FOLLOWING THE NAVEL),}

female genital mutilation. The age increase will help to avoid circumstances where young people are placed in potentially vulnerable situations, particularly where there is risk to the developing body. ${ }^{13}$

\section{Complications}

Unsurprisingly, oral and peri-oral piercings are associated with numerous complications. The UK incidence of complications associated with oral piercings is reported by Bone et al. (2008). ${ }^{2}$ In 16-24-year-olds, 50.1\% who had tongue piercings and $20.5 \%$ who had lip piercings experienced complications. Tongue piercing was the second most common body piercing resulting in complications (following the navel). This finding corroborates other studies which state that complications are most prevalent with tongue piercings, followed by lip, cheek and gingivae., ${ }^{3,14,15}$
It is currently unknown how many patients with oral piercings attend for emergency treatment in the UK. In 2006, a UK-based survey of 126 piercees reported that $99 \%$ had problems with their tongue piercing, $7 \%$ of which required healthcare following the piercing. ${ }^{16}$ A US study of 100 emergency departments has reported an estimated annual presentation rate of 3,494 injuries associated with oral piercings. ${ }^{14}$ In this study, patients aged 14 to 22 years old accounted for $73 \%$ of the emergency visits.

Several investigations have aimed to identify the prevalence of the different complications associated with oral piercings (Table 1).

Commonly reported acute complications include pain, swelling, haemorrhage, infection and masticatory and speech impairment. Less frequently reported immediate complications include haematoma, delayed healing, puncture wound, laceration, dental trauma, allergy, dysphagia and hypersalivation. ${ }^{14,15,17-21}$ Commonly reported chronic complications include pain, infection, swelling, bleeding, tissue hyperplasia, soft tissue trauma, gingival recession, dental trauma, dental pain, speech impairment, taste disturbances and ingestion of piercing. Less frequently reported chronic complications include masticatory/eating impairment, gingivitis, plaque accumulation (Fig. 5), hypersalivation, galvanic reaction, tooth migration and dysphagia. ${ }^{14,16-21}$ Complications have been shown to be more common in patients who habitually play with their piercing. ${ }^{15}$

Several rare and sometimes serious oral piercing complications have been reported (Table 2). ${ }^{22}$ Prior to the enforcement of COSHH regulations, it was hypothesised that oral piercings could increase the risk of transmission of blood borne viruses such as HIV and hepatitis $\mathrm{B}$ and $\mathrm{C}^{23}$

It is essential that all professions who encounter oral piercings are properly informed and able to provide advice regarding oral piercing complications. The level of advice offered by UK dental professionals regarding oral piercings is currently unknown. There is no current consensus among dental professionals regarding the type of complications that should be discussed with patients. There many easily available advice leaflets developed for the piercing industry, however similar documentation does not exist for the dental profession. To investigate the current knowledge, attitudes and behaviours of UK dentists regarding advice provided to patients with oral piercings, a survey was distributed to GDPs in Wales. The results are discussed, and advice is provided for dental professionals treating patients with oral piercings. 
ARTICLE

Table 1 Commonly reported complications of oral and peri-oral piercings in the dental and medical literature (cont. on p22)

Study

De Moor et al. $2005^{17}$

Patient questionnaire + examination

Levin et al. $2005^{19}$

Patient questionnaire + examination

Chadwick et al. 2005

Dentist questionnaire

Stead et al. $2006^{10}$

Patient questionnaire

Vieira et al. $2010^{2}$

Patient questionnaire + examination

Number of
patients Number of piercings

50

55

(47 tongue; 8 lip)

\section{Acute}

Frequency of oral piercing complications

\% Chronic \%

Swelling

22 Speech impairment

\begin{tabular}{|l|l|l|l}
\hline Pain & 14 & Eating impairment & 10
\end{tabular}

H

Haematoma

4 Soft tissue trauma

10

Infection 2

Delayed healing $\quad 2$

Haemorrhage $\quad 2$

\begin{tabular}{|l|r|l|r|}
\hline Swelling & 52.9 & Gingival recession & 26.6 \\
\hline
\end{tabular}

Haemorrhage

79

79

- Not reported

126 (tongue)

\begin{tabular}{|l|r|l|l}
\hline Swelling & 90 & Ingest piercing & 29 \\
\hline Pain & 69 & Dental trauma & 28 \\
\hline
\end{tabular}

\begin{tabular}{|l|l|l|l}
\hline Eating impairment & 63 & Plaque deposits & 26 \\
\hline
\end{tabular}

Speech impairment

43 Speech impairment

Haemorrhage

Ingest piercing

42 Swelling

Dental trauma

Plaque deposits

5 Eating impairment

Pain

4 Bleeding

Haemorrhage

\begin{tabular}{|l|l|l|l}
\hline Pain & 52.4 & Soft tissue trauma & 64.3 \\
\hline
\end{tabular}

\begin{tabular}{l|l|l|l}
\hline Faint & 4.8 & Swelling & 61.9 \\
\hline
\end{tabular}

42

(37 tongue; 5 lip)

\begin{tabular}{|l|r|}
\hline Infection & 38.1 \\
\hline Dental pain & 33.3 \\
\hline Tissue hyperplasia & 31 \\
\hline Bleeding & 28.6 \\
\hline Gingival recession & 4.8 \\
\hline Dental trauma & 2.4 \\
\hline
\end{tabular}


Table 1 Commonly reported complications of oral and peri-oral piercings in the dental and medical literature (cont. from p21)

\begin{tabular}{|c|c|c|c|c|c|c|}
\hline \multirow{2}{*}{ Study } & \multirow{2}{*}{$\begin{array}{r}\text { Number of } \\
\text { patients }\end{array}$} & \multirow{2}{*}{ Number of piercings } & \multicolumn{4}{|c|}{ Frequency of oral piercing complications } \\
\hline & & & Acute & $\%$ & Chronic & $\%$ \\
\hline \multirow{5}{*}{$\begin{array}{l}\text { Hickey et al. } 2010^{15} \\
\text { Patient questionnaire + examination }\end{array}$} & \multirow{5}{*}{201} & \multirow{5}{*}{$\begin{array}{r}201 \\
\text { (106 tongue; } 88 \text { lip; } 7 \\
\text { cheek) }\end{array}$} & Eating impairment & 78.3 & Gingival recession & 14.8 \\
\hline & & & Speech impairment & 67 & Taste disturbance & 12.3 \\
\hline & & & Swelling & 51.7 & Dental trauma & 7 \\
\hline & & & Dysphagia & 28.4 & & \\
\hline & & & Hypersalivation & 20.4 & & \\
\hline \multirow{7}{*}{$\begin{array}{l}\text { Gill et al. } 2012^{14} \\
\text { Retrospective epidemiological study }\end{array}$} & \multirow{7}{*}{24,459} & \multirow{7}{*}{$\begin{array}{r}24,459 \\
\text { (10,341 tongue; } \\
11,197 \text { lip; } 2,921 \text { other) }\end{array}$} & Infection & 42 & \multirow{7}{*}{ Not reported } & \\
\hline & & & Puncture wound & 29 & & \\
\hline & & & Laceration & 10 & & \\
\hline & & & Haemorrhage & 7 & & \\
\hline & & & Dental trauma & 7 & & \\
\hline & & & Haematoma & 1 & & \\
\hline & & & Allergy & 1 & & \\
\hline \multirow{9}{*}{$\begin{array}{l}\text { Plessas et al. } 2012^{22} \\
\text { Patient questionnaire + examination }\end{array}$} & \multirow{9}{*}{110} & \multirow{9}{*}{$\begin{array}{r}161 \\
\text { (51 tongue; } 110 \text { lip) }\end{array}$} & Pain & 57.7 & Ingest piercing & 48 \\
\hline & & & Eating impairment & 49 & Gingival recession & 39.7 \\
\hline & & & Speech impairment & 33.5 & Bleeding & 33 \\
\hline & & & Haemorrhage & 4.3 & Dental trauma & 32.3 \\
\hline & & & & & Plaque deposits & 21 \\
\hline & & & & & Dental pain & 13 \\
\hline & & & & & Hypersalivation & 9.3 \\
\hline & & & & & Taste disturbance & 6.8 \\
\hline & & & & & Galvanic reaction & 3 \\
\hline
\end{tabular}

Table 2 Rare complications of oral and peri-oral piercings ${ }^{22}$

\begin{tabular}{|c|c|}
\hline Complication & $\begin{array}{l}\text { Number of } \\
\text { case reports }\end{array}$ \\
\hline Periodontitis & 11 \\
\hline Endocarditis & 8 \\
\hline Hypotensive collapse & 1 \\
\hline Loss of insertion needle & 1 \\
\hline Ludwig's angina & 1 \\
\hline Fatal herpes simplex hepatitis & 1 \\
\hline $\begin{array}{l}\text { Thrombophlebitis of sigmoid } \\
\text { sinus }\end{array}$ & 1 \\
\hline Atypical trigeminal neuralgia & 1 \\
\hline Bifid tongue & 1 \\
\hline Airway obstruction & 1 \\
\hline Cerebral abscess & 1 \\
\hline Tetanus infection & 1 \\
\hline
\end{tabular}

\section{Fig. 6 Example of questionnaire sent to GDPs}

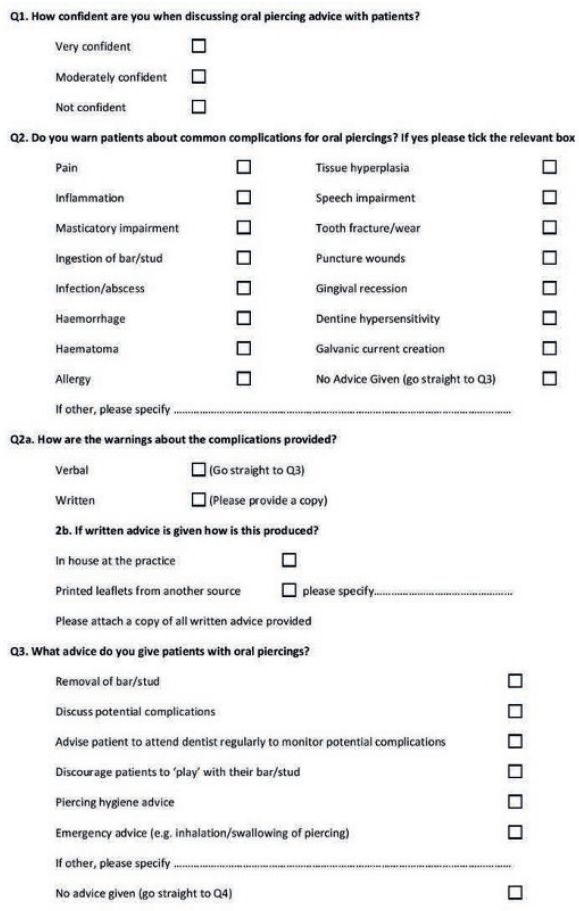


Fig. 7 GDP confidence in delivering orofacial piercing education to patients

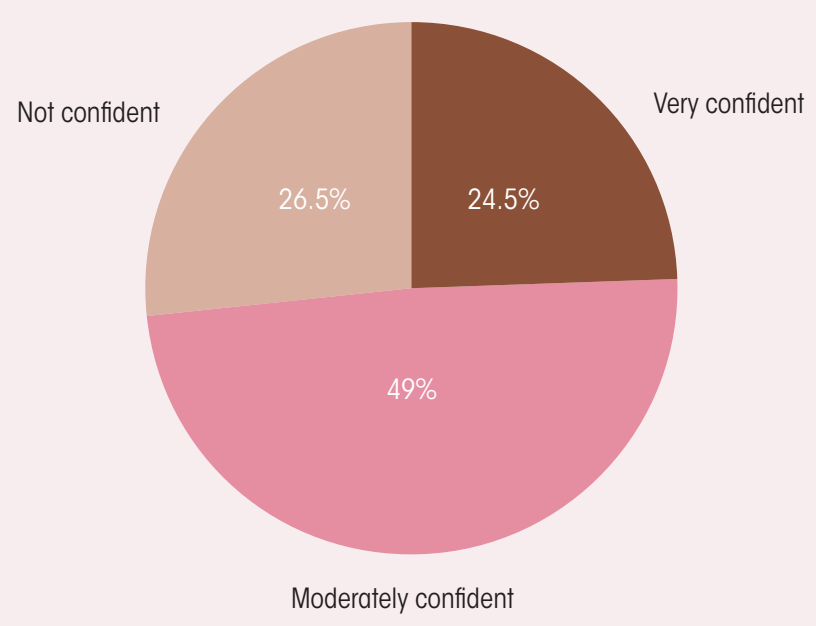

\section{Methodology}

A multiple-choice questionnaire was developed with the aim of documenting dentists' perceived confidence in discussing oral piercings, information provided to patients regarding complications, methods used to provide patients with information, sources dentists are using to acquire their knowledge and whether further support or information is required. An example of the questionnaire is presented in Figure 6.

Inclusion criteria consisted of GDPs working in primary care in the Betsi Cadwaladr University Health Board (North Wales) and the Bro Taf Health Authority (covering Cardiff, Merthyr Tydfil, Rhondda Cynon Taff and the Vale of Glamorgan in South Wales). The questionnaire was sent via electronic mail using Microsoft Office Software.

\section{Results}

Two hundred GDPs were approached to complete the questionnaire with a total of 53 GDPs (26.5\%) returning completed surveys. Results were collated and analysed using Microsoft Excel.

\section{GDP confidence}

When asked how respondents felt about discussing oral piercing advice with patients, $24.5 \%(\mathrm{~N}=13)$ replied very confident, $49 \%$ $(\mathrm{N}=26)$ were moderately confident and $26.5 \%$ $(\mathrm{N}=14)$ not confident (Fig. 7). Information provided to patients has predominantly been acquired from experience $(\mathrm{N}=39,73.6 \%)$, and to a lesser extent from dental training $(\mathrm{N}=9$, 17.0\%). As part of their Continuing Professional Development (CPD), some GDPs have also read published literature on the topic $(\mathrm{N}=15,28.3 \%)$ and one had researched their local authority publications.

\section{Complications}

Warnings of piercing complications are given by 50 (94.3\%) of the respondents, all of whom given verbal advice only. The three GDPs (5.7\%) who do not offer any information had also answered that they were not confident in discussing advice with patients.

There were 15 complications described in the survey, illustrated by Figure 8 . None of the respondents offered additional examples. Understandably the most common complications discussed were trauma to teeth $(\mathrm{N}=46)$, gingival recession $(64.1 \%$, $\mathrm{N}=34$ ), and dentine hypersensitivity (22.6\%, $\mathrm{N}=12$ ). Aside from dental-related trauma, GDPs tend to warn of acute complications such as infection $(52.8 \%, \mathrm{~N}=28)$, inflammation $(37.7 \%, \mathrm{~N}=20)$, and pain (28.3\%, N = 15). Chronic complications, such as scarring/ tissue hyperplasia (16.9\%, $\mathrm{N}=9$ ), are described less often.

When complications arise, 19 GDPs (35.8\%) would advise on where to seek treatment. In the first instance, the majority $(24.5 \%, \mathrm{~N}=13)$ recommend seeking treatment from a dentist. Secondary to this, patients are directed to either return to their piercer $(13.2 \%, \mathrm{~N}=7)$, attend with their general medical practitioner $(11.3 \%, \mathrm{~N}=6)$, or seek attention from their local emergency department $(13.2 \%, \mathrm{~N}=7)$.

\section{Piercing advice}

A large proportion of GDPs offered additional guidance $(94.3 \%, \mathrm{~N}=50)$, demonstrated in

Fig. 8 Orofacial piercing complications described to patients by GDPs

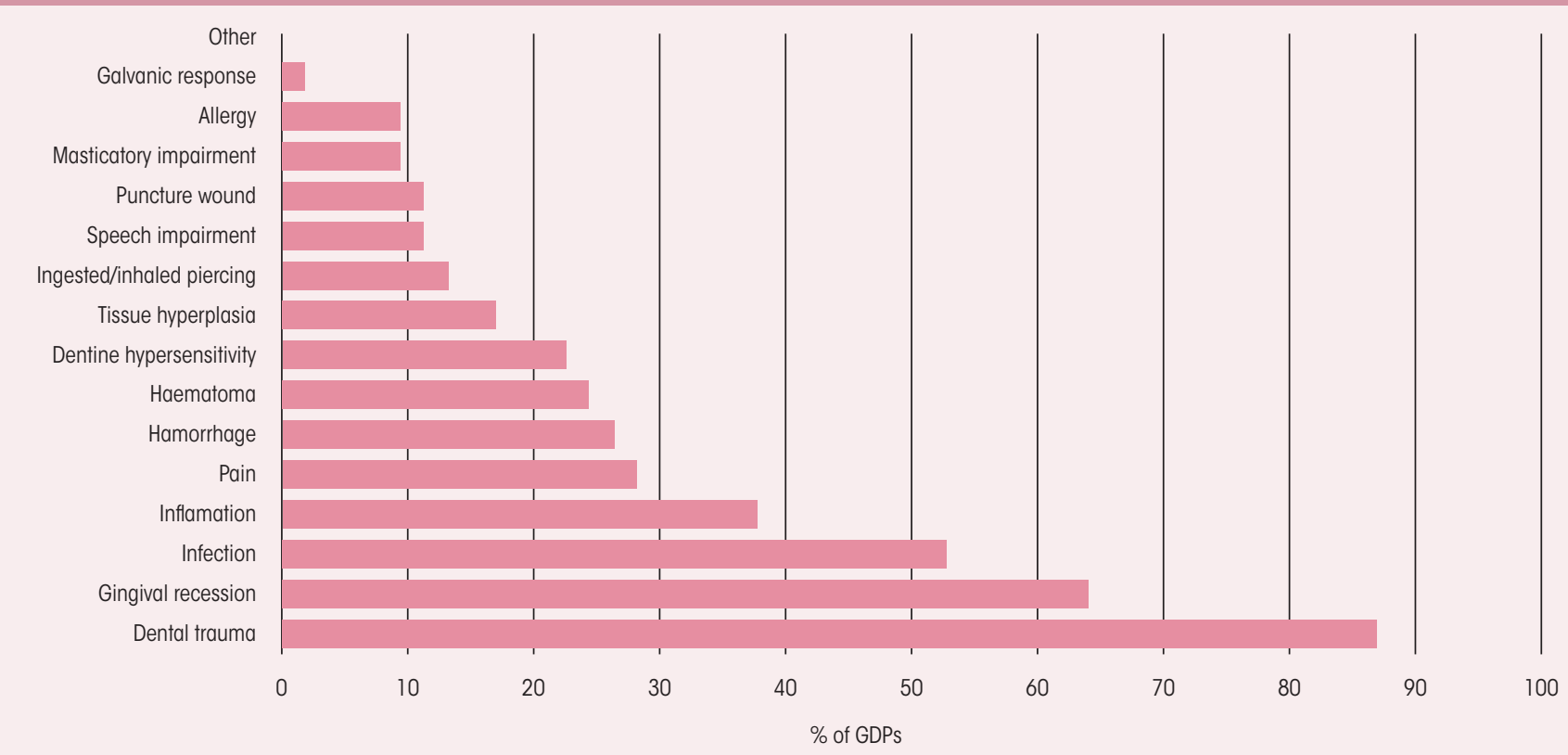




\section{Fig. 9 Orofacial piercing advice given to patients by GDPs}

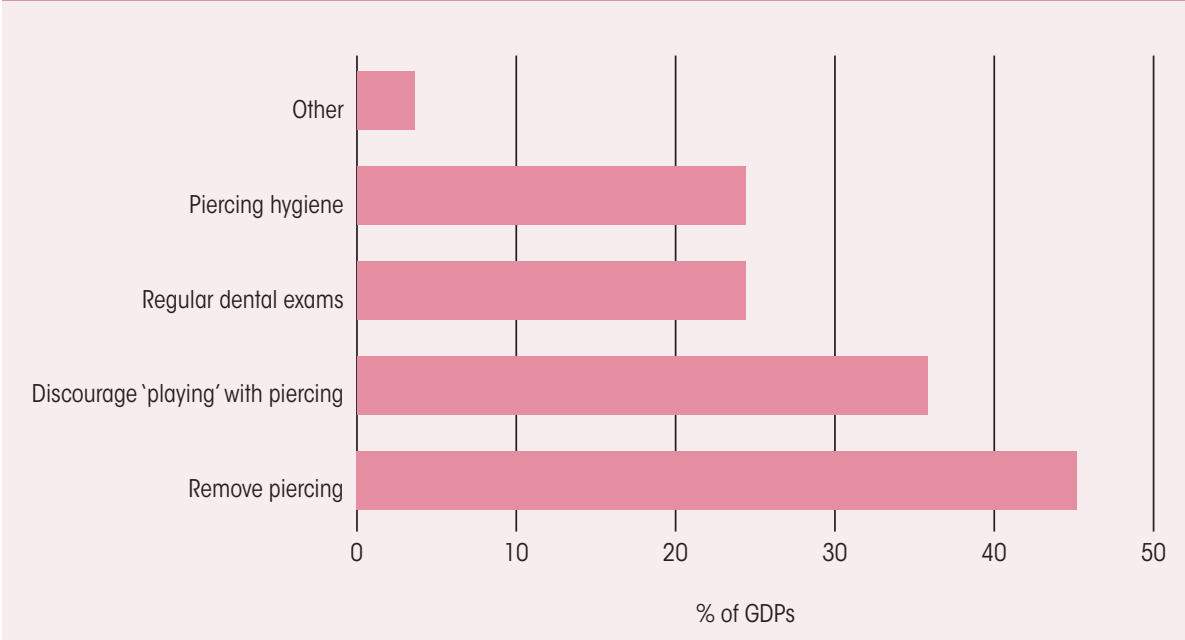

Fig. 10 Advice CDPs would like to receive in relation to the management of orofacial piercings

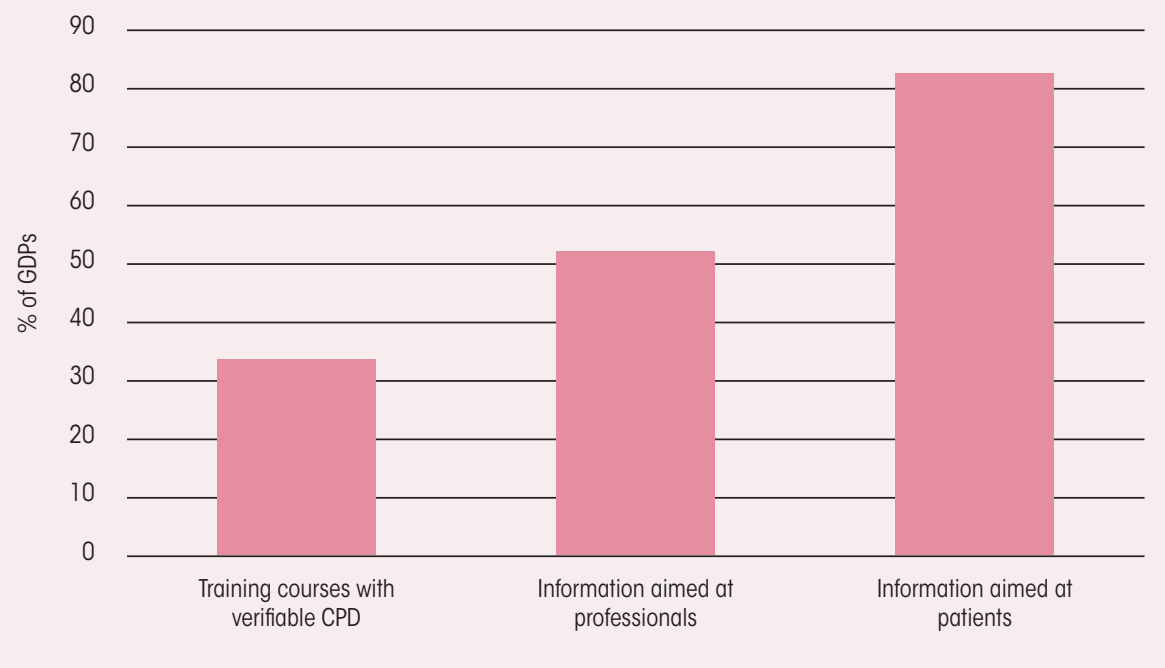

GDPs reporting they developed knowledge through formal training or reading dental Figure 9. The three GDPs (5.7\%) who lacked confidence acknowledged that they do not discuss oral piercings with patients.

Advice is largely based on minimising the risk of trauma to intra-oral tissues, hence GDPs often advocate removing piercings $(45.2 \%, \mathrm{~N}=24)$. Two respondents who offered 'Other' information recommend replacing metallic components of piercings with plastic alternatives, particularly if there is 'evidence of damage to the lower anterior teeth.' A quarter of GDPs advise that patients attend for regular dental examinations to monitor potential problems $(24.5 \%, \mathrm{~N}=13)$. Where piercings are kept in situ, patients are discouraged from regularly 'playing' with or touching/rotating the piercing $(35.8 \%, \mathrm{~N}=19)$. Hygiene guidance is provided by $13(24.5 \%)$ respondents.

Again, the preferred method of delivering advice is verbally ( $\mathrm{N}=44,83.0 \%)$. One respondent (1.9\%) stated that they offer written information, which is produced inhouse at the practice. A copy of this written advice was not offered on return of the survey. A number $(\mathrm{N}=8,15.1 \%)$ of GDPs did not specify how their advice is delivered.

\section{GDP support}

GDPs were asked what advice they would like to receive in relation to managing oral piercings in dental practice, summarised in Figure 10. Largely, respondents preferred printed information directed towards patients $(\mathrm{N}=44$, 83.0\%). Just over half of GDPs indicated that they would like printed information aimed at professionals $(\mathrm{N}=28,52.8 \%)$, and $18(34.0 \%)$ would like training courses that provide

Lastly, GDPs were asked their opinion of existing publications relating to oral piercings. Of the responses, 20 (37.7\%) felt that available publications are sufficient; however, verifiable CPD. observations were made that materials are not readily accessible. One individual remarked that they 'could not find information on where to seek help if serious infection occurred.' A total of 13 (24.5\%) respondents felt that current publications are insufficient, with two commenting that they hadn't seen piercingrelated documents before this survey. Two GDPs specified that patient information is inadequate. A proportion of GDPs were unfamiliar with any publications $(15.1 \%, \mathrm{~N}=8)$.

\section{Discussion \\ Prevalence}

The increasing incidence of oral piercings appears to be a world-wide phenomenon. A 2012 systematic review studied the prevalence of oral piercings in young adults from the United Kingdom, Canada, Brazil, Spain, Israel, the United States of America, New Zealand, Germany and Finland. The results revealed that $5.2 \%$ of the 9,104 young adults had an oral piercing. ${ }^{3}$ The trend for such piercings was higher in women $(5.6 \%)$ than men $(1.6 \%)$ (M:F = 3:11), with the most popular piercing being the tongue (5.6\%) followed by lips (1.5\%) and cheeks $(0.1 \%)$. Oral piercings are most common in 16-30 year olds. ${ }^{2,3}$ Alarmingly, several studies report oral piercings in individuals as young as 11-14 years of age., $3,14,17,24$

Bone et al. $(2008)^{2}$ published the only study that estimates the prevalence of body piercings in the United Kingdom. This survey of 10,503 adults found that $2.1 \%$ had a piercing of the lip or tongue. When looking specifically at 16-24-year-olds, $9.2 \%$ reported piercings of the lip and/or tongue. Females (2.5\%) were more likely than males (1.5\%) to opt for these types of piercings (M:F ratio 3:5). Most piercees received their piercing at a dedicated studio. Similar evidence suggests around $80 \%$ of piercings take place in piercing establishments. ${ }^{25}$

A 2016 survey was conducted by the Oral Health Foundation, an independent UK oral health charity, to establish the current trends of oral piercings in the UK. ${ }^{26}$ Of 214 respondents, tongue piercings were the most commonly reported (43\%), followed by lip (33\%). Additionally, other anatomical sites were described: frenulum (7\%), cheek (3\%) and sites such as gingival piercings. $13 \%$ of people with oral piercings had more than one intra-oral site pierced, highlighting their existing popularity among the UK population.

The increased prevalence of oral piercings has not gone unnoticed by the dental profession. A UK survey of 227 dentists in South Wales revealed that $99 \%$ of dentists had treated a patient with an oral piercing, over three-quarters (77.5\%) had seen a 
patient for a complication caused by the piercing, and over half (52.9\%) had treated an oral piercing complication. ${ }^{18}$ The British Dental Association (BDA) released a position statement in 2009 which advises against oral piercings, and recommends that individuals with a piercing should regularly visit a dentist and self-monitor the piercing site for complications. ${ }^{27}$ Although the prevalence of oral piercings is on the rise, the results from this survey suggest that the confidence and knowledge within the dental profession regarding oral piercings is not evolving with this trend. It is therefore felt by the authors that more should be done to educate the dental profession about oral piercings.

\section{Awareness}

Piercee awareness of potential oral piercing complications varies. One study of 110 piercees reported $70.9 \%$ were unaware that oral piercings could affect their general health and $26.4 \%$ were unaware of potential dental complications. ${ }^{24}$ Similar studies have reported that around $46-57.8 \%$ of piercees are unaware of the complications associated with oral piercings. ${ }^{19,21}$

Information should initially be provided by the establishment performing the piercing, both before consenting an individual and after performing the piercing. Encouragingly, a recent UK survey of piercers in South Wales reported $100 \%$ of piercers provided advice regarding oral piercing complications, with $57 \%$ giving both verbal and written warnings, $36 \%$ giving verbal only, and $7 \%$ providing written warnings only. ${ }^{28}$ However, warnings given by piercing studios were diverse and no one piercer discussed all relevant complications. Interestingly $79 \%$ of piercers reported that further information aimed at both piercing professionals and piercees would be beneficial.

\section{Confidence among the dental profession}

It is evident from the results of this survey that only a quarter of GDPs are very confident in discussing with patients the nature of oral piercing complications and necessary preventative advice. In comparison, a similar UK survey conducted by Chadwick (2005) ${ }^{18}$ reported that nearly $88 \%$ of dentists felt they could give adequate advice regarding possible complications to patients who were considering having an oral piercing. This suggests confidence among the profession has fallen, which may be a result of the increased prevalence and complexity of oral piercings.

Most respondents disclosed that their knowledge regarding oral piercings was learnt from experience, with only a small number of

Fig. 11 Advice leaflet developed for dental professionals to discuss oral piercing complications with patients. Courtesy of 1000 Lives Service Improvement Dental Team

\section{$1000_{\text {OFYWS L I I }}^{\text {LIVAU }}$}

Oral Piercings - Guidance for Dental Professionals
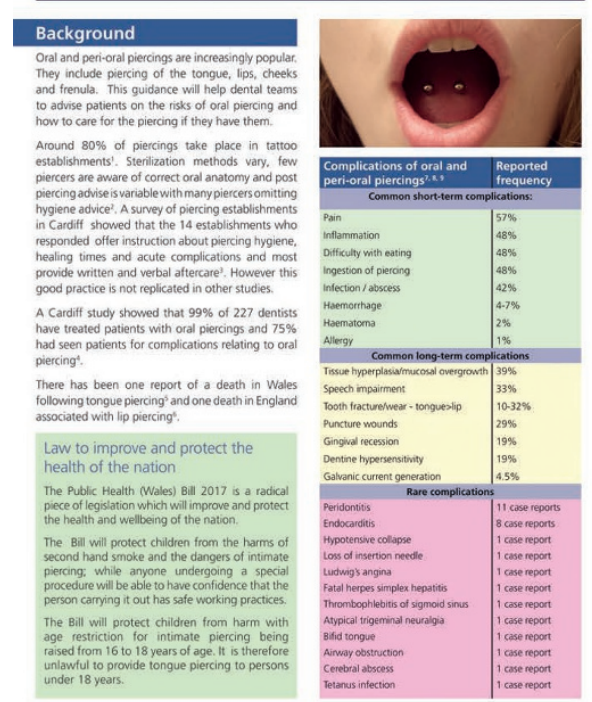

$1000 \frac{\text { LIVES }}{\text { OFWTOAU }}$

Oral Piercings - Guidance for Dental Professionals

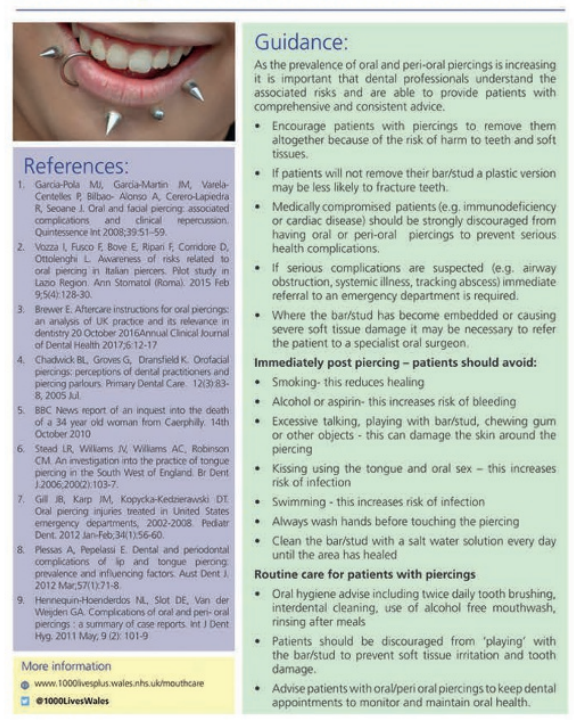

\section{MORE SHOULD BE DONE TO EDUCATE}

\section{THE DENTAL PROFESSION ABOUT ORAL}

\section{PIERCINGS...}

literature. This suggests there is a lack of access to information and training available for dentists in the UK. Furthermore, a large proportion of respondents reported they would like information leaflets available for their patients. Many reported they would like to receive further information aimed at dentists and felt that there is a need for CPD courses for dental professionals. This highlights an area of dental education which may currently be insufficient for dental professionals to feel confident giving oral piercing advice and treating complications.

It was reassuring to discover that the majority of GDPs are providing patients with verbal advice regarding oral piercing complications. As one would expect, GDPs responded that they regularly discuss dental related complications. Other common acute and chronic complications appear to be discussed much less frequently. This concurs with the UK study by Chadwick (2005), ${ }^{18}$ whereby tooth fracture and recession were the most commonly discussed complications between GDPs and patients. ${ }^{18}$ It is apparent that in over ten years there has not been any development in the information provided by GDPs to patients regarding oral piercing complications. As a visit to a dental professional is an opportune moment for patients to receive oral health advice, it is felt by the authors that more needs to be done to empower dental professionals to discuss the range of complications associated with oral piercings.

Encouragingly, almost all GDPs reported the provision of preventative advice to avoid oral piercing complications for their patients. However, the advice regarding how to prevent complications and where complications should be treated varied among GDPs. It is currently unknown how frequently piercees in the UK seek medical or dental attention for oral piercing complications. Considering an estimated 2\% of adults in the UK have an oral piercing, it is likely that a large proportion of this group of patients will require some level of medical or dental care at some point. ${ }^{2}$ This therefore emphasises the importance of the provision of clear and comprehensive preventative advice for patients to reduce the likelihood of complications.

As GDPs feel that current publications are insufficient and have indicated that they would like further information available for patients and dental professionals, the authors of this article, together with 1000 Live Wales, have developed patient information leaflets which have been distributed to GDPs in Wales to enable them to discuss complications with patients and provide written advice (Fig. 13). It is important that all dental professionals possess 
the appropriate skills and knowledge to treat patients with oral piercings and are confident to provide the correct advice.

\section{Limitations}

As with all studies, there are certain limitations that need to be recognized in this survey. Firstly, the low response rate of $26.5 \%$ meant that a large proportion of dentists' experiences and opinions were not captured in the data which may have affected the results. It is possible that contacting dentists via email led to a poorer response rate than that which may have been achieved by using a printed version of the survey sent via post. It is also possible that due to the large number of surveys dentists receive, the GDPs targeted in this study may have experienced 'survey fatigue' which affected response rates. The variation in prevalence of oral piercings in the different Welsh regions targeted for this survey is unknown. It is therefore possible that the GDPs who responded may see a low number of patients with oral piercings which may explain the low confidence and experience treating piercing related complications.

\section{Conclusion}

Oral piercings are associated with numerous complications, and it is possible that the incidence of complications may increase as the prevalence of oral piercings rises in the UK population. It is important that dental professionals can provide patients with appropriate advice and manage oral piercing complications that may arise. The results of this survey suggest that dental professionals are not entirely confident discussing risks and preventative advice with patients. To address this issue, patient information leaflets have been developed to encourage dentists to discuss complications associated with oral piercings with patients.

\section{Acknowledgements}

The authors would like to thank the 1000 Lives Wales team for help distributing the survey and designing the information leaflet.

1. Chen M, Scully C. Tongue piercing: a new fad in body art. Br Dent J 1992; 172: 87.

2. Bone A, Ncube F, Nichols T, Noah N D. Body piercing in England: a survey of piercing at sites other than earlobe. $B M J$ 2008; 336: 1426-1428.

3. Hennequin-Hoenderdos N L, Slot D E, Van der Weijden G A. The prevalence of oral and peri-oral piercings in young adults: a systematic review. Int J Dent Hyg 2012; 10: 223-228.

4. Griffith R, Tengnah C. Public health 3: Legal regulation of tattooing and body art. $\mathrm{Br}$
J Community Nurs. 2005; 10: 575-579.

5. Parliament. House of Commons. Body piercing. Bound Volume Hansard. 2033; Column 467-469.

6. British Body Piercing Association. Advice and safe practice for body piercing Guidance for operators. 2008.

7. Health and safety at work act 1974 . Available at http://www.hse.gov.uk/legislation/hswa. htm (accessed July 2017).

8. Local Government (Miscellaneous Provisions) Act 1982: Elizabeth II. The Stationery Office, 1982.

9. Control of Substances Hazardous to Health 2002. Available at http://www.hse.gov.uk/ coshh/ (accessed July 2017).

10. Derbyshire County Council 2016 Derbyshire Children's Homes Procedures Manual Contents. 5.18 Tattooing and Body Piercing Policy. Available at http:// www.proceduresonline.com/derbyshire/ ch_homes/chapters/p_tattoo_piercing. html\#bpunder (accessed July 2017).

11. Rotherham Metropolitan Borough Council 2016 Rotherham Safeguarding Children and Families Procedures Manual. 7.7.3 Tattooing and Body Piercing Policy. Available at http:// rotherhamcsyp.proceduresonline.com/p_ tattoo_policy.html (accessed July 2017).

12. Castle Point Borough Council. Body Piercing Guidelines. Available at https://www. castlepoint.gov.uk/licensing-of-treatments (accessed July 2017)

13. National Assembly for Wales. 16 is too young for intimate piercings - says National Assembly committee. 2017. Available at http://www.assembly.wales/en/newhome/ pages/newsitem.aspx?itemid $=1685$ (accessed July 2017).

14. Gill J B, Karp J M, Kopycka-Kedzierawski D T. Oral piercing injuries treated in United States emergency departments, 2002-2008. Paediatr Dent 2012; 34: 56-60.

15. Hickey B M, Schoch E A, Bigeard L, Musset A M. Complications following oral piercing. A study among 201 young adults in Strasbourg, France. Community Dent Health 2010; 27: 35-40.

16. Stead L R, Williams J V, Williams A C, Robinson C M. An investigation into the practice of tongue piercing in the South West of England. Br Dent J 2006; 200: 103-107.

17. De Moor R J, De Witte A M, Delmé K I, De Bruyne M A, Hommez G M, Goyvaerts D. Dental and oral complications of lip and tongue piercings. Br Dent J 2005; 199: 506509.

18. Chadwick B L, Groves G, Dransfield K. Orofacial Piercings: Perceptions of Dental Practitioners and Piercing Parlours. Prim Dent Care 2005; 12: 83-88.
19. Levin L, Zadik Y, Becker T. Oral and dental complications of intra-oral piercing. Dent Traumatol 2005; 21: 341-343.

20. Plessas A, Pepelassi E. Dental and periodontal complications of lip and tongue piercing: prevalence and influencing factors. Aust Dent J 2012; 57: 71-78.

21. Vieira E P, Ribeiro A L, Pinheiro Jde J, Alves Sde M Jr. Oral piercings: immediate and late complications. J Oral Maxillofac Surg 2011; 69: 3032-3037.

22. Hennequin-Hoenderdos N L, Slot D E, Van der Weijden G A. Complications of oral and peri-oral piercings: a summary of case reports. Int J Dent Hyg 2011; 9: 101-109.

23. Pugatch D, Mileno M, Rich J D. Possible transmission of human immunodeficiency virus type 1 from body piercing. Clin Infect Dis 1998; 26: 767-768.

24. Greif J, Hewit W, Armstrong M L. Tattooing and body piercing: body art practices among college students. Clin Nurs Res 1999; 8: 368-385.

25. Garcia-Pola M J, Garcia-Martin J M, Varela-Centelles P, Bilbao-Alonso A, Cerero-Lapiedra R, Seoane J. Oral and facial piercing: associated complications and clinical repercussion. Quintessence Int 2008; 39: $51-59$.

26. Oral Health Foundation. Your Say Survey Question, 'What kind of oral piercing do you have?'. 2016; Sample 214.

27. British Dental Association. British Dental Association position statement. Tongue piercing. Available at https://www.bda.org/ dentists/policy-campaigns/public-healthscience/public-health/position-statements/ Pages/tonguepiercing.aspx (accessed July 2017).

28. Brewer E A. Aftercare Instructions for Ora Piercings: An Analysis of UK Practice and its Relevance in Dentistry. Ann Clin J Dent Health 2017; 6: 12-17.

This article was originally published in the $\mathrm{BDJ}$ (Volume 224 pages 887-895, 8 June 2018). Reproduced with kind permission.

\section{CPD questions}

This article has four CPD questions attached to it which will earn you one hour of verifiable CPD. To access the free BDA CPD hub, go to https:// cpd.bda.org/login/index.php 